\title{
Rich Scientific Publications: Design Guide Based on Cognitive Framework
}

\author{
Camila Wohlmuth da Silva \\ FCT Universidade Nova de Lisboa \\ Quinta da Torre, Caparica, Portugal \\ cw.silva@campus.fct.unl.pt
}

\author{
Nuno Correia \\ FCT Universidade Nova de Lisboa \\ Quinta da Torre, Caparica, Portugal \\ nmc@fct.unl.pt
}

\begin{abstract}
There is a growth of interactive multimedia publications in the scientific context as well as a demand to discover the advantages of multimodal user interaction with this type of publication. Along these lines, this work in progress presents a design guide based on the development of a cognitive framework, principles of design and concepts of interactivity to promote the user's easier understanding when trying to complement or reinforce the information through interactive multimedia integration. This guide will be further applied and tested in the construction of a model for rich scientific publications.
\end{abstract}

Cognitive science, Interactive technology, Information presentation and visualization.

\section{INTRODUCTION}

The scientific publications are part of encoding scientific studies and have become increasingly dependent on technological functions for its visibility; the object itself, scientific journals are being modified, offering new possibilities of access and new ways of presenting scientific content, as more dynamic and interactive (Owen, 2006). This allows greater flexibility and range of applications compared to the traditional system of scientific publications (Owen, 2006). As an example, additional multimedia content can be seen in publications such as ACM SIGGRAPH which has expanded to become an international community with a focus on computer graphics and interactive techniques (ACM SIGGRAPH, 2018).

Therefore, the use of multimedia and interactive resources by certain publications in hypermedia can be observed. Although there is not yet a guide to rich scientific publications, many scientific communities are striving to create interactive scientific journals. Elsevier and Plos One have developed interactive scientific publishing. In the Elsevier platform publications, 2D / 3D data can be viewed as well as animated videos in Plos One (da Silva C.W., Correia N., 2017). It is important to highlight that the hypermedia systems can be complex, enabling communication through multimedia formats and interaction modalities (Chambel et al., 2006). Interactive multimedia introduces another level of complexity by bringing the temporal dimension into the text.
Therefore, the researcher then becomes an immersive reader changing its relationship with scientific content, mobilizes various cognitive efforts and different intensities for the reading process and its form. There is an absence of literature regarding the relationship of the user's cognitive system and the inclusion of interactive multimedia in scientific publications. Hence, the purpose of the study is to create a guide for rich scientific publications from design principles and cognitive science. It is important to find a cognitive structure that can provide the basis for design, according to previous theories and interactivity studies, providing researchers with understanding and learning (Chambel et al., 2006).

The article is divided into the following sections: 2 . Interactive environment, to understand the context in which scientific publications are inserted; 2.1 Interactivity, which deals with the types of interactivities that can be applied in the guide; 3 . Cognitive theories, which address the main cognitive theories, they are 3.1 Cognitive Load Theory, 3.2 Dual Code Theory, 3.3 Cognitive Theory of Multimedia Learning; 4. Cognitive Framework presents the relationship between theories and their contributions to creating a framework to be applied to the guide; 5. Design Guide demonstrates the guide based on the cognitive framework and according to the precepts of interface design to organize the interactive multimedia. Finally, 6. Conclusions and Future Works are explained. 


\section{INTERACTIVE ENVIRONMENT}

In a digital environment, the integration of multimedia constitutes a more participatory publication in hypermedia systems. Generally, this type of publication is driven by interactive features that enable different navigations in a nonlinear, meaningful way (Siegel et al., 2013). How fast and easy it is for the researcher to understand an article is one of the main criteria for determining the success or failure of interactive scientific publications. From this format, referring to the three aesthetic categories: immersion, agency, and transformation (Murray, 2003). The agency effect has been the major concern for the design of interactivity since it determines the course of the information and is directly related to the intention of the researcher's actions by following videos, images, internal or external links, resulting in the interaction movement.

\subsection{Interactivity}

The concept of "interactivity" is synthesized as an equation: communication + choice = interactivity (Kristof, Santran, 2010). The guide has two major concepts of interactivity and also classify the type of interactive environment, such as arboreal and hypermedia models. Accordingly, the user can manipulate, exploit, or influence content in a variety of options, and that content can respond. The specific type of interactivity that is taking place in the scientific publications guide is coactive - there is a possibility for the user to control the sequence, rhythm, and style (Reisman, 2002). It is proactive as well when the user has the capability to control both the structure and the content (Reisman, 2002).

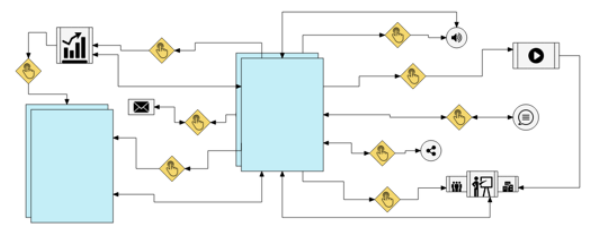

Figure 1: Types of interactivity suggested by the guide

Furthermore, the interface for the proposed guide has five types of interactivity, (1) linear interactivity: it offers a pre-established and sequential interaction, the user can advance, stop or return to information, the relation between text and videos, animations, images, and others; (2) arborescent interactivity: related to the presentation of the information in a hierarchical way, the user can select the information through menus or other tools; (3) linguistic interactivity: consists of the use of keywords, forms, etc., for access to information; (4) creation interactivity: allows the user to compose a message by correspondence; (5) continuous command interactivity: enables the user to modify and move textual, sound and visual objects (Landow,1997).

\section{COGNITIVE THEORIES}

\subsection{Cognitive Load Theory}

The Cognitive Load Theory (Sweller, 1994) asserts to promote learning, namely those that take advantage of the multimedia potentialities. Just as the studies published by George Miller (1955) referred to a "magic number" $7-2$ or $7+2$, the human cognitive system can process only a limited amount of information ranging from 5 to 9 elements simultaneously. When these limits are exceeded, reasoning and understanding are below the desired performance, overloading the cognitive structure (Santos; Tarouca, 2007).

According to Mayer (2009), multimedia applications consist of resources that use more than one channel of perception simultaneously, often generating disorientation and lack of stimulation on the part of the user. The Cognitive Load Theory, as stated by Mayer (2009), is based on three assumptions: 1 . The human being has two distinct channels for information processing: the visual channel and the verbal channel; 2 . There is a limited capacity of information processing in each channel; 3 . Learning requires analytical cognitive processing in both channels. To promote high-quality understanding, a balance is needed between the loads that enhance the efficiency of content comprehension. The content should be carried out, allowing autonomy in the intervals between segments or, prior instruction on the system.

\subsection{Dual Code Theory}

The Dual Code Theory (DCT) attempts to give equal weight to verbal and non-verbal processing. Paivio (1991) provides a dual coding explanation of bilingual processing, according to the author, human cognition involves the activity of two separate and specialized systems to represent and process information, a verbal system to deal with language and, a non-verbal system specialized in processing non-linguistic events and objects. If there is new information to process, these subsystems adapt themselves to the different modalities (Chambel et al., 2006). The theory identified three types of processing: Representational, the direct activation of verbal or non-verbal representations, Referential, the activation of the verbal system by the nonverbal system or vice-versa, and Associative processing, the activation of representations within the same verbal or nonverbal system (Paivio, 1991). A task can establish any or all three types of processing. The success of scientific publication in multimedia support can be due to the DCT and its additive and multiplicative effect. Moreover, because of this double storage capacity, information communicated to a person, both verbally and pictorially, it is possible to be remembered than information that comes in only one format (Galitz, 2007). 


\subsection{Cognitive Theory of Multimedia Learning}

Mayer (2009) addresses a theory about media integration based on human information processing and cognitive theories. In Mayer's theory, there are basic assumptions that are essential for the understanding of multimedia in human cognition. Limited capacity assumption, when humans are limited concerning the amount of information they can process simultaneously (Chambel et al., 2006). Dual coding theory (Pavio, 1991), relates auditory and visual information, which are processed separately in working memory. Processing assumption, where human beings actively process incoming information by selecting relevant information and constructing coherent mental representations (Chambel et al., 2006).

\section{COGNITIVE FRAMEWORK}

Cognitive framework can define the design guide to create an effective interactive multimedia application of rich scientific publications. Thus, the first two theories described above differ in regards to audio storage: the first suggests that the verbal audio and displayed text are stored together; the second suggests that they should be stored separately (Mayer, 2009). In learning elaborate processing, there is another consideration summarized by Bailey (2001), "elaborate" means that people take more time to analyze and store information, and this auxiliary integration of extra cognitive processing of material with prior knowledge develops learning. Based on these studies, the previous theories, Clark and Mayer (2008), as well as Moreno and Mayer (2000), studies they were combined and related for application in rich scientific publications:

(i) User understanding occurs most significantly with multiple representations when combining words and images rather than words alone.

(ii) Users better comprehend visual information if there is the principle of modality, for instance, visual information is accompanied by audio narration, instead of only text.

(iii) The presentation of text and animation on the same screen can divide the user's attention. Users have an enhanced understanding when verbal and visual materials are temporally synchronized; there must be temporal contiguity, the written or narrated text must appear simultaneously with the image.

(iv) Users organize information more efficiently when there is spatial contiguity with increased understanding when on-screen text and visual materials are physically integrated; that is, they are close to each other in view of the fact that the construction of a reference frame between them is allowed.

(v) Redundant information should not be used when utilizing complementing sources. It is preferable to employ animation and narration simultaneously rather than separately (they cannot divide attention). The inclusion of the same information in a verbal and non-verbal form does not reinforce learning.

(vi) The information is not coherent when it is unused content with a non-relevant cognitive load, i.e., words, images or sounds are not required for understanding multimedia explanations, which should be excluded. The users working memory needs to be available to process information.

(vii) Users understand better when the articles do not require split attention between multiple sources of mutually referring information (both visual or verbal). For example, avoid any animation that diverts the user's attention from the most important information, limit the disclosed information to one item at a time, and sequentially divulge related elements.

(viii) The publication should pay attention to individual user differences; it is difficult to find a group of users with similar skill sets, organization and content processing. Therefore, it is fundamental to have a tutorial in order to show the action to be performed, as well as the resulting action.

\section{DESIGN GUIDE}

The guide organizes the interactive multimedia and makes interactivity the key point of understanding scientific information. In addition, it defines how content is organized within interactive systems in a structured way, and how the system responds to user actions (Houge, 2010). The guide is based on the cognitive needs and desires of the user. It understands the goals, tasks, experiences (Houge, 2010), as well as the capabilities provided by interactive multimedia resources. Further, it seeks to establish a relationship between researchers and rich scientific publications that are perceived to be useful and valuable (Houge, 2010). As follows, it addresses interactive work with basic elements to create various user experiences, such as manipulating objects (highlight text, alter shape or size and drag), engaging in interactive searches and interacting with the authors. In this way, five basic types of interactivity, common to the digital environment, are presented:

- Stimulus and response: clicking and viewing an animation sequence, audio, video, image in slides and animated graphics; 
- Navigation: it allows the mobility of the researcher between pages and multimedia content;

- Control objects: hide or activate the interactive object, increase and decrease the size of the content, utilize the pause and play options, control volume, insert subtitle text and notes;

- Communication: through e-mail to the author, chat, user actions or dialog menus;

- Exchange information: sending or sharing.

For all of these types of interactivity to be effective, it is fundamental to communicate to the users what functions are available and allows them to infer by interacting with what they see. Furthermore, it gives the user a clear sense of workflow, preventing users from making too many mistakes through smart defaults and appropriate visual design controls.

Table 1: Caveats for the application of interactive multimedia elements (adapted from Gibbs, 2014)

\begin{tabular}{|l|l|}
\hline Application in Rich Scientific Publications \\
\hline Consistency & $\begin{array}{l}\text { The publication must be sensitive to } \\
\text { change. As long as persistent } \\
\text { elements remain in the same place, } \\
\text { retain the same appearance, and } \\
\text { adhere to the same grid layout. }\end{array}$ \\
\hline Perceivability & $\begin{array}{l}\text { Perception invites interaction. The } \\
\text { interaction is perceived as intuitive, } \\
\text { as rapidly perceived interactions } \\
\text { increase usability and publication } \\
\text { efficiency. }\end{array}$ \\
\hline Learnability & $\begin{array}{l}\text { Interactions should be quick learning } \\
\text { and easy to remember. Ideally, } \\
\text { users should be able to use a } \\
\text { scientific publication interface once, } \\
\text { learn it and retain it. }\end{array}$ \\
\hline Predictability & $\begin{array}{l}\text { A suitable interaction design should } \\
\text { provide recognition of interactions } \\
\text { and information about the results. }\end{array}$ \\
\hline Feedback & $\begin{array}{l}\text { Feedback is used to understand } \\
\text { where the user is, their current } \\
\text { status, what to do next, and even } \\
\text { know how long it will take. Feedback } \\
\text { should complement the experience. }\end{array}$ \\
\hline
\end{tabular}

Finally, the diagram below illustrates some possible applications to elucidate the guide for rich scientific publications, with the possible multimedia applications and links, as well as the functionalities required to present and share information efficiently with the researcher. Static media is represented in yellow and dynamic media in orange. The static media mutually integrates with dynamic media, because the users organize information more efficiently and increase understanding when there is spatial contiguity. The multimedia is close to each other, physically integrated, in view of the fact that the construction of a reference frame between them is allowed. Furthermore, to capture the user's attention, the information is systematically revealed.

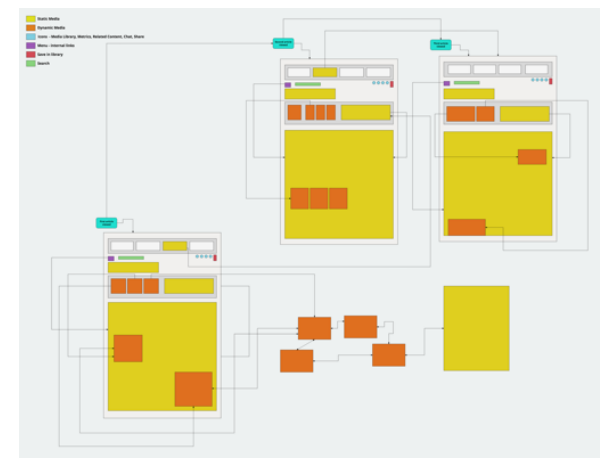

Figure 2: Mental structure of guide option

The diagram also shows some suggestions for navigation and interaction for the publications. One of the suggestions is the use of the menu (in purple), which presents the anticipation of the information intended for the user. The user has the possibility to navigate in arborescent interactivity according to the informational needs. The other suggestion is to use a library, which stores multimedia data and saved articles (in red in the diagram). In regards to saved articles, it is a one-to-many connection, which is advantageous because saved articles can be reconsidered and browsed without the need to download or apply a new keyword search. The guide improves user understanding as the verbal and visual contents are temporarily synchronized. It also relates to the principle of modality, in which users better understand visual information if accompanied by audio narration, rather than just the text on the screen. The structure of the scientific publications should attend to the user differences. The guide suggests that the scientific publications take the use of tutorials in order to show the action to be performed, as well as the resulting action.

\section{CONCLUSIONS AND FUTURE WORKS}

The need to use interactive multimedia resources in the presentation of scientific information and its communication is increasing, since, the normal speed of scientific evolution has given way to the real, instantaneous, exchange of multimedia information. Multimedia as a tool is a powerful source for gaining the attention of researchers, adding interests and quickly transmitting information that is harder to present verbatim. In this way, the guide proposed in this article has the intention of creating a solid cognitive structure coupled with the principles of design and the concepts of interactivity to contribute and promote a better and faster understanding of scientific content. The next stage will be to apply this guide to a scientific publication and create usability tests in order to validate and corroborate the improvement of this work. 


\section{REFERENCES}

Owen J. M. (2006). The Scientific Article in the Age of Digitization. Information Science and Knowledge Management, Vol. 11. p. 263 Springer.

ACM SIGGRAPH. (2018). Association for Computing Machinery (ACM) SIGGRAPH. https://www.siggraph.org/about/about-acmsiggraph.

Silva C.W., Correia N. (2017). Analysis of Interactive Multimedia Features in Scientific Publication Platforms. In: Kamps J., Tsakonas G., Manolopoulos Y., Iliadis L., Karydis I. (eds) Research and Advanced Technology for Digital Libraries. TPDL 2017. Lecture Notes in Computer Science, vol 10450. Springer, Cham

Chambel, T., Zahn, C., Finke, M. (2006). Hypervideo and Cognition: Designing VideoBased Hypermedia for Individual Learning and Collaborative Knowledge Building, in Alkalifa, E. ed., Cognitively Informed Systems: Utilizing Practical Approaches to Enrich Information Presentation and Transfer, Idea Group Publishing, pp.26-49.

Siegel, E. R.; Lindberg, D. A. B.; Campbell, G. P.; Harless, W. G.; Godwin, C. R. (2010). Defining the next generation journal. The NLM- Elsevier interactive publications experiment Information Services and Use, v. 30, n. 1-2, p. 17-30.

Murray, J. H. (2003). Hamlet no holodeck: o futuro da narrativa no ciberspaço. São Paulo: UNESP.

Kristof, R.; Satran, A. (2010). Interactivity by Design: Creating and Communicating with New Media. Mountain View: Adobe, 1995. In: Gosciola, V. Roteiro para as novas mídias. 2. ed. São Paulo: Senac São Paulo, 2010.

Reisman, R. R. (2002). Rethinking Interactive TV I want my Coative TV. A White Paper by Richard R. Reisman, President, Teleshuttle Corporation. http://www.teleshuttle.com/cotv/cotvintrowtpaper. $\mathrm{htm}$

Landow, G. (1997). Hypertext 2.0: the convergence of contemporary critical theory and technology. Baltimore: The Johns Hopkins.

Sweller, J. (1994). Cognitive Load Theory, learning difficulty, and instructional design. Learning and Instruction 4: 295-312.

Miller, G. A. (1955). The Magical Number Seven, Plus or Minus Two: Some Limits on Our Capacity for Processing Information. Psychological Review, Vol. 101, No. 2, pp.343 352.
Santos, L. M. A; Tarouca, L. M. R. (2007) A importância do estudo da teoria da carga cognitiva em uma educação tecnológica. PGIE/UFRGS.

Mayer, R. E. (2009). Multimedia Learning $\left(2^{\text {nd }} e d\right)$. Cambridge: Cambridge University Press.

Paivio, A. (1991). Dual Coding Theory: retrospect and current status. Canadian Journal of Psychology, 45(3), 255-287.

Galitz, Wilbert O. (2007). The Essential Guide to User Interface Design: An Introduction to GUI Design Principles and Techniques. Indiana: Wiley Pyblishing, Inc.

Bailey, R. W. Multimedia and Learning. Web Usability. (2001). In: Galitz, W. O. The Essential Guide to User Interface Design - An Introduction to GUI Design Principles and Techniques. Indiana: Wiley Pyblishing, Inc., 2007. p. 687.

Clark R. C,; Mayer, E.R., (2008). E-learning and the Science of Instruction: Proven guidelines for consumers and designers of multimedia learning. San Francisco: Pfeiffer.

Moreno R.; Mayer E.R., (2000). A learner-centered approach to multimedia explanations: Deriving instructional design principles from cognitive theory, Interactive Multimedia Electronic Journal of Computer-Enhanced Learning, 2000, 2(2): Epub.

Houge, D. (2010). Interaction Design for Graphic Designers. MAX, San Francisco. http://www.idux.com/downloads/MAX2010_HOG UE_Interaction_Design_Principles.pdf

Gibbs, I. (2014). Principles of Interaction Design. https://info.obsglobal.com/blog/2014/08/the-fiveprinciples-of-interaction-design

Norman, D. (2013). The Design of Everyday Things. Revised and Expanded Edition. A Member of the Perseus Books Group, New York. 